\title{
Thoughts on the Construction of Volunteer Team in Shaanxi History Museum
}

\author{
Ying Ren \\ Xi'an University \\ Xi'an, China
}

\begin{abstract}
Museum volunteers play an irreplaceable role in the service of museum industry, the development of cultural relic and museum career and the tertiary industry in the public sphere. They take the society masses as the basic strength and serve the society masses at the same time. But in the process of team building, there are some limitations inevitably, such as the incomplete volunteer management system and service system. Therefore, for the construction of museum volunteer team, it is necessary to sum up experience in continuous practice and exploration. Combined with the characteristics of volunteers, they should seek a road suitable for scientific development, strengthen the management of volunteers, and promote the publicity of volunteer service, so as to promote the further development of museum volunteer team construction and better serve the community and tourists.
\end{abstract}

Keywords-Shaanxi History Museum; volunteer team; construction; thought

\section{INTRODUCTION}

Since the 20th century, the development of museum business has gradually entered the public view. Museums across the country have become hot spots of cultural and public concern. With the dramatic increase in the number of museums and the opening of museums throughout China free of charge since 2007, the number of visitors is increasing, which brings more severe challenges to museum workers. In order to relieve the pressure of work, museums have been expanding the recruitment of volunteers in recent years to provide better and qualified service for tourists. However, with the increase of museum volunteers, various problems also follow. In view of the investigation and analysis of current situation of volunteers in Shaanxi History Museum, this paper will have some thoughts and put forward some suggestions on volunteer team construction in Shaanxi History Museum, hoping to better serve the society and tourists and achieve their own value.

\section{QUESTIONNAIRE ABOUT VOLUNTEER TEAM OF SHAANXI HISTORY MUSEUM}

Shaanxi History Museum (hereinafter referred to as SHM) is China's first large modern museum opened in 1991. As the history of physical evidence, the archaeological treasures of Shaanxi from prehistoric times to Qing Dynasty are systematically displayed here, giving the visitors an extremely rich visual feast. It has been 19 years since SHM launched volunteer work in 1999 . Nearly 6,000 volunteers have worked in SHM with selfless dedication, serving millions of tourists and alleviating the urgent need of the museum to a certain extent. What is the current situation of the volunteers in SHM? With this question, in January 2018, the author issued the questionnaires to the volunteers in SHM. However, because the service times of museum volunteers are not centralized, random sampling method is used to investigate and summarize the data. 87 questionnaires were distributed and 84 were recovered, with a recovery rate of $96 \%$. The situation is as follows:

- Gender characteristics: $33 \%$ of volunteers surveyed were men, $67 \%$ were women, and women were almost twice as many as men.

- $\quad$ Age and occupation: 18 to 30-year- old volunteers accounted for $88 \%$, most of volunteers are college students; 30 to 50-year-old volunteers accounted for $6 \%$, most of who were public servants; $6 \%$ of volunteers aged over 50, who are mainly retired workers. From this, we can see that college students are the main composition of SHM volunteers.

- Ways of joining: There are two ways to recruit volunteers in SHM. The college students are recruited through school clubs to join the volunteer team, accounting for $87 \%$; the number of personnel recruited from the society is relatively small, accounting for $13 \%$.

- Working time: The surveyed volunteers, who worked for more than one year in SHM, account for $25 \%$, over half a year account for $9 \%$, more than three months account for $19 \%$, and only one or two times account for $8 \%$. The data show that the volunteer mobility of museum is relatively large, and the number of staff who worked for a long time is relatively low.

- Service content: volunteer interpretation service accounted for $42 \%$; voluntary consultation service accounted for $30 \%$, voluntary logistics services and guided services accounted for $14 \%$.

- Subsidy award: $12 \%$ of volunteers surveyed believe that the museum should reimburse the related expenses (such as bus costs); 29\% think that volunteer work is a voluntary contribution; $51 \%$ suggest that 
appropriate incentives should be set up to improve volunteer work enthusiasm; $8 \%$ think that it should be considered depending on individual circumstances.

- Dealing with problems: $53 \%$ of volunteers will seek help from other staff; $44 \%$ of them will make an honest apology that he/she has no idea; $3 \%$ will find other ways to solve the problem.

- Areas for improvement: In the construction of volunteer team in the museum, the surveyed volunteers who considered that there should be a selection process accounted for $12 \%$; training work accounted for 50\%; management measures accounted for $30 \%$, and other aspects accounted for $8 \%$.

\section{PROBLEMS IN CONSTRUCTION OF SHM VOLUNTEER TEAM}

From the analysis of organization and management of volunteers in SHM, it can seen that although the volunteers play an important role in the museum's educational function, there are still many problems in the work of Museum volunteers due to the limitations of social conditions and reality, which are mainly manifested in the following aspects:

First, the composition of volunteers is relatively simple. They are mainly college students, and has only a small part of volunteers from social recruitment. But the service time of college students is relatively fixed, usually on weekends and holidays. And about $90 \%$ of them signed a one-year service agreement with a one-year period, but most people cannot stick to the work for a long term, with large fluidity. For example, the volunteers of SHM will recruit a lot of "fresh blood" every year, and they need a period of time to adapt to work. Secondly, the volunteer activity is generally spontaneously organized by college students. They take it as social practice that can be credited to certain credits. But there is no relevant supervision system in schools, and museums often make a lot of efforts to train volunteers. And some volunteers gave up halfway because of the hardships of work [1]. To some extent, this wastes the museum's time and energy, so the recruitment of volunteers needs further planning and improvement of the museum.

Second, there are difficulties in volunteer training. There usually have simple selection training to college student volunteers in colleges, and then a number of professional training is carried out by the museum. Initially this method plays a good role in the cycle. However, with the gradual development of museum industry, the museum has attached more importance to volunteer service. And its work content is widespread and more and more people join the volunteer team. From the beginning of a single explanation to the present consultation, tour guide, logistics, all aspects need volunteers to help work. However, the museum did not make specific analysis and arrange training work according to the individual situation of volunteers. Instead, it adopts a unified training mode, mainly interpretation and reception work. The forms and methods of training are monotonous, without specific work content, and the purpose of training is very strong voluntary interpretation. In terms of other jobs, volunteers are simple learning after work, which is also the reason why the training cannot achieve good results.

Third, the management system of museum volunteers is not perfect, and relevant laws and regulations are missing. While foreign museums attach more importance and expertise in management, which take volunteer management as an important part of museum work. In foreign museums, a special volunteer office or person in charge is set up as "volunteer coordinator". They will regularly check volunteers' work and apply for welfare activities for volunteers, etc. But Chinese museums only depend on the museum's behavior standards to restrict volunteers. For example, the fourth page of SHM volunteer service manual clearly stipulates the behavior standards for each volunteer, a total of eight articles. There is no protection for volunteers' rights and interests, so some people have called for the protection of volunteers' rights and interests on the Internet and published articles [2].

Forth, the volunteers' autonomy is relatively small, and the sense of belonging to the museum is not strong. The work of museum volunteers in China is mainly arranged directly by museums according to venues, cultural relics, posts and tourist saturation. And they cannot arrange the service items specifically according to the personal professional and hobbies of volunteers, ignoring the autonomy of volunteers. During the volunteer work is arranged in SHM, the cultural relic's exhibition halls are allocated on the basis of individual wishes, only for voluntary interpretation. And other aspects need to be improved. In addition, volunteers have a high mobility and cannot continue to work in museums, so they lack a certain sense of belonging to museums. Moreover, museum administrators lack of the necessary spiritual comfort and communication for volunteers, and they do not have enough awareness of spiritual encouragement and value recognition [3]. Some museum staff cannot understand the volunteers correctly and give them respect. Considering volunteer work only as a supplement to human resources in museums is not conducive to enhancing the enthusiasm of volunteers.

\section{SUGGestions On STRENGTHENING CONSTRUCTION OF VOLUNTEERS IN SHM}

\section{A. Increasing Publicity and Establishing a Good Image}

At present, museum visitors have a big blind zone for volunteers in museums. They do not understand the content of volunteer work, and often directly seek help from the staff when encountering difficulties. However, no one cares the volunteers arranged by the museum to be consulted by tourists. There is a "volunteer garden" column on the official website of SHM to publish the activities of volunteers, but little achievement is got. Therefore, museums need to increase the publicity of volunteers, carry out some promotional activities with characteristics, and establish a good image for volunteers For example, the influence of volunteers on museums and the public can be enhanced by shooting and editing videos or photographs of volunteers serving tourists, through the museum display screens to play. 


\section{B. Expanding Recruitment Channels and Refining the Selection Process}

The recruitment of volunteers is a public welfare activity of the whole society, which can be publicized by the museums on the Internet. The potential resource institutions of some volunteers can be sought, and the museums can get close contact and support from them. And the museums should sign a certain safeguard agreement with them, on the one hand to ensure the rights of volunteers, on the other hand to provide adequate human resources for the museum. For example, cooperative relations can be established with colleges, social organizations and business organizations at all levels around the museum, so as to mobilize people interested in the knowledge of historical relics and volunteer activities to enroll in the recruitment of museum volunteers. This can guarantee the quality resources of volunteers to a large extent.

\section{Strengthening Training Links and Improving Volunteer Quality}

The training stage is generally divided into initial training and pre-job professional training, in which volunteers need to be trained in cultural relics knowledge, etiquette skills and reception services. But the volunteers are huge, and it is difficult to take care of everyone during training. In view of the problems in training, museums need to be improved in two ways: on the one hand, the service content should be distributed according to the volunteers' personal preferences and professional orientation, which not only can enhance the volunteers' own skills but also can improve their enthusiasm for service; on the other hand, museums must combine their own characteristics and reality to work out a reasonable and effective training program for volunteers, carrying out and continuously adjusting the training of volunteers according to the development of the museum, and improving the comprehensive quality of volunteers. In this way, an excellent team of museum volunteers can be built.

\section{Constructing Guarantee System and Improving the Volunteer Management System}

SHM has done a remarkable job in the recruit, training and remuneration of volunteers but its management on the college students, the main body of volunteers is still not in position. The museum can try to negotiate with college for mutual coordination to implement joint management of both parties. Establish a community with one college volunteer team as unit, the college leader as responsible person and close connection with museum and jointly select a serious and responsible volunteer as the team leader who shall be responsible for the work connections between volunteers on the team and the museum which enables the museum to only need to communicate with the team leader to issue work arrangement. Then the leader will communicate with volunteers in a more detailed way so as to conduct efficient and orderly management, simplify the work procedures and form the mutual benign interactions between colleges and museum.

\section{E. Improving the Incentive System and Stabilizing the Volunteer Team}

Volunteer refers to the free services and the unrequited works which origin from loving heart and spirit of utter devotion. However, the volunteer works in museum is the career needing long-term persistence which cannot be maintained by temporary enthusiasm and loving heart. This requires the establishment of a certain incentive system to motivate the passion of volunteers. The museum can satisfy the demands of volunteers from two aspects including economic benefits and spiritual motivation. For example, on the aspect of economic benefit, the museum can reimburse some related expenses for volunteers such as travel allowance, carry out the working lunch for volunteers, set up the post of paid expostor and prefer to consider the qualified volunteers; on the aspect of spiritual motivation, the museum can establish the praise publicity system and add credits for the college volunteers, etc so as to improve the enthusiasm of volunteers and preferably realize the social values of museum.

\section{CONCLUSION}

In a word, museum volunteers are the main carriers for the museum to give play to the function of education, which embodies the realization of "three-close" thought of the museum (close to reality, close to life and close to the mass) and is also the important part on the museum industrial advance road. The volunteers wearing red waistcoats, wearing red hats and making selfless contributions are like the glowing flame burning at every corner in the museum and become the beautiful and special scenery line in museum. They serve the society with loving heart and promote the development of public welfare establishments. Sure, the construction of museum volunteer teams still needs continuous exploration and practice and shall advance with the times and combine with the practical conditions to formulate the development activity plans of volunteers so as to promote the healthy growth of "volunteer teams".

\section{REFERENCES}

[1] Lan Guoying, Yang Ling. Study on the Volunteer Activities of Museum in China[J]. Cultural Relics of the East, Vol. 20, Hangzhou: Hangzhou University Press, 2006 (3): 120.

[2] Voluntary Services Needing Legislation[EB/OL]. http://www. people.com.cn/, 2001-12-05; Legislation: Opening the protective umbrella for voluntary services [EB/OL]. http://www. people.com.cn/, 2001-12-07.

[3] Bu Yan. Brief Analysis on the Standardized Management of Museum Volunteers [J]. Wen Bo, Xi'an: Shanxi People's Publishing House, 2014 (5), 73. 